\section{Health effects among workers in sewage treatment plants}

Ragnar Rylander
The workers could usually connect the appearance of symptoms to a particular work task involving exposure to an aerosol of sewage water or sewage sludge. The workers also had an increased amount of fibrinogen degradation products (FDP) in urine and higher amounts of serum transaminase (ASAT), suggestive of an ongoing inflammation. It was suggested that the causative agent responsible for the symptoms may be bacterial toxins.

Another questionnaire study was undertaken among 189 workers in municipal sewage treatment plants and drinking water plants in New York. ${ }^{6}$ They found that workers reported an increased frequency of headache, dizziness, sore throat, skin irritation, and diarrhoea after correction for age, sex, smoking, and alcohol habits. Workers with increased concentrations of urinary mutagens were more likely to report skin irritation. In a study from Zagreb, respiratory symptoms and ventilatory capacity was investigated among 74 sewage workers. ${ }^{7}$ The extent of airway symptoms was higher for sewage workers, and baseline ventilatory capacity was decreased.

Although the first study focused on the presence of bacterial toxins, the others focused on chemical agents as the cause of the symptoms. Although chemical agents may or may not be present, depending on the type of effluent received, microbial contamination is always present. Gram negative bacteria are dominant, ${ }^{5}$ and airborne endotoxin is thus present. This is an agent with well known inflammatory properties, and exposure to it has been related to toxic pneumonitis as well as airways inflammation. ( $1 \rightarrow 3)-\beta-\mathrm{D}$-glucan from moulds is another microbial cell wall component with documented effects on the inflammatory system. $^{8}$

The present study was undertaken to further elucidate the exposure to endotoxin and $(1 \rightarrow 3)-\beta-D$-glucan, and the presence of inflammatory responses among workers in sewage water treatment plants.

\section{Materials and methods}

The investigation was performed among employees in eight sewage treatment plants in four municipalities in the south of Sweden. In each plant, different work sites were investigated. All people working in the plants were invited to participate and all accepted. Controls were 
Table 1 Population characteristics

\begin{tabular}{lrrrrr}
\hline & \multicolumn{2}{c}{ Controls } & & \multicolumn{2}{c}{ Workers } \\
\cline { 2 - 3 } \cline { 5 - 6 } \cline { 5 - 6 } & $n$ & $\%$ & & $n$ & $\%$ \\
\hline All & 35 & - & & 34 & - \\
Men & 30 & 91 & & 31 & 86 \\
Women & 5 & 14 & & 3 & 9 \\
Non-smokers & 18 & 51 & & 16 & 47 \\
Past smokers & 14 & 40 & & 13 & 38 \\
Smokers & 3 & 9 & & 5 & 15 \\
\hline
\end{tabular}

from personnel lists at municipal work sites where there was no exposure to waste water or organic dusts. Table 1 presents background data for the people investigated. The workers and the controls were similar for the characteristics indicated.

\section{EXPOSURE}

Measurements were made of the amounts of airborne $(1 \rightarrow 3)-\beta-D$-glucan and endotoxin. The workers alternated daily between several worksites and for practical reasons, it was not possible to perform personal sampling measurements. Instead filters were placed at different worksites in the plants visited regularly during an ordinary working day. The air was sampled by drawing air through Isopore filters (ATTP $0.8 \mu \mathrm{m}$, Millipore, Cambridge, MA, USA) at a flow rate of $5 \mathrm{l} / \mathrm{min}$ for 30 minutes.

The amount of airborne $(1 \rightarrow 3)-\beta$-D-glucan and endotoxin was determined by shaking the filters for 10 minutes in $10 \mathrm{ml}$ pyrogen free water. A sample was set aside for later analyses of endotoxins. Thereafter, $0.3 \mathrm{M} \mathrm{NaOH}$ was added, and the filters were shaken on ice for 10 minutes to unwind the triple helix structure of the glucan and make it water soluble. The extracting solutions from the filters were analysed for $(1 \rightarrow 3)-\beta$-D-glucan and endotoxin with specific Limulus lysates. ${ }^{9}$

Filter extract samples of $50 \mu \mathrm{l}$ were placed in a microwell plate, and $50 \mu \mathrm{l}$ specific glucan lysate (Fungitec G Test, Seikagaku, Tokyo, Japan) or specific endotoxin lysate (Endospecy) were added. The plate was incubated in a spectrophotometer (Scinics Corp, Tokyo, Japan), and the kinetics of the ensuing colour reaction was read photometrically, transformed into absorbency units, and compared with a standard curve. The results were expressed as $\mathrm{ng} / \mathrm{ml}$ liquid. With the value for air flow through the filter, these results were transformed to $\mathrm{ng} / \mathrm{m}^{3}$. The detection limit for this technique is $10 \mathrm{pg} / \mathrm{ml}$ for endotoxin and 20 $\mathrm{pg} / \mathrm{ml}$ for $(1 \rightarrow 3)-\beta-\mathrm{D}$-glucan. The coefficient of variation for this method was $1.22 \%$.

\section{QUESTIONNAIRE}

The subjects were interviewed with a slightly modified standard questionnaire for the assessment of organic effects induced by dust which has been used in several previous investigations. ${ }^{10}$ The questionnaire contained a series of questions on existing diseases, earlier work in a dusty environment, duration of employment at the present work site, the type of work carried out, and if personal protection (filter masks) was used. This was followed by a series of questions on different symptoms, present at least one third of the time "Do you regularly (more than one third of the time) have the following symptoms". The symptoms were cough, dry or with phlegm, chest tightness, shortness of breath, irritation in the eyes, nose, or throat, and nose congestion and itchy nose. Questions were also posed on joint pains, muscle pains, headache, unusual tiredness, wheezy chest, skin problems, nausea, and diarrhoea. Special questions related to subjective airway reactivity, chronic bronchitis, asthma, and episodes of fever and influenzalike symptoms that were gone the next day. Differences in extent of symptoms between groups were calculated with the $\chi^{2}$ test.

Spirometry and airway responsiveness

Spirometry was performed with standard techniques. A Vitalograph model $S$ with a pulmonary function test (PFT) printer was used and was calibrated every morning with a 11 syringe. The test group performed at least three technically acceptable trials, and the largest value for the forced expiratory volume in one second $\left(\mathrm{FEV}_{1}\right)$ was registered and compared with predicted values. ${ }^{11}$

Airway responsiveness was assessed with the methacholine challenge test according to Yan et $a l,{ }^{12}$ with some modifications. Spirometry was performed to exclude people with $<70 \%$ of predicted values in $\mathrm{FEV}_{1}$ or in $\mathrm{FEV}_{1} / \mathrm{FVC}$. A Pari Boy nebuliser with automatic dosing was used to make the methacholine into an aerosol. The nebuliser was calibrated, and the automatic output was adjusted to give $3 \mu 1 /$ dose. The test person exhaled to slightly less than functional residual capacity, placed the nebuliser in the mouth, opened the mouth without closing the lips around the nebuliser and started to inhale. At maximum inhalation, the breath was held for 3 seconds before exhaling. One minute after inhalation, the maximum FVC and $\mathrm{FEV}_{1}$ were recorded.

The subjects initially inhaled one dose of saline. The spirometric values obtained one minute after this inhalation were used as the baseline values for the methacholine test. The methacholine was given in increasing doses at 3 minute intervals up to a total amount of 1.2 mg. The FVC and $\mathrm{FEV}_{1}$ were recorded one minute after each dose of methacholine. In cases in which $\mathrm{FEV}_{1}$ decreased by $>10 \%$ from the baseline value after one dose, a slower increase in dose levels was given. If $\mathrm{FEV}_{1}$ decreased $>20 \%$ from the baseline value after any dose of methacholine, the test was discontinued. The results were expressed as the group average decrease in $\mathrm{FEV}_{1}$ after the highest dose of methacholine given. All subjects completed the test and the differences between the groups were evaluated with the Student's $t$ test.

\section{Results}

The amounts of airborne endotoxin in the two control worksites were normal background concentrations $\left(1.2\right.$ and $\left.3.4 \mathrm{ng} / \mathrm{m}^{3}\right)$. At the sewage plant worksites, the values were very different between different sites and between different plants, depending upon ventilation, the use of pumps to aerate the water, and the 


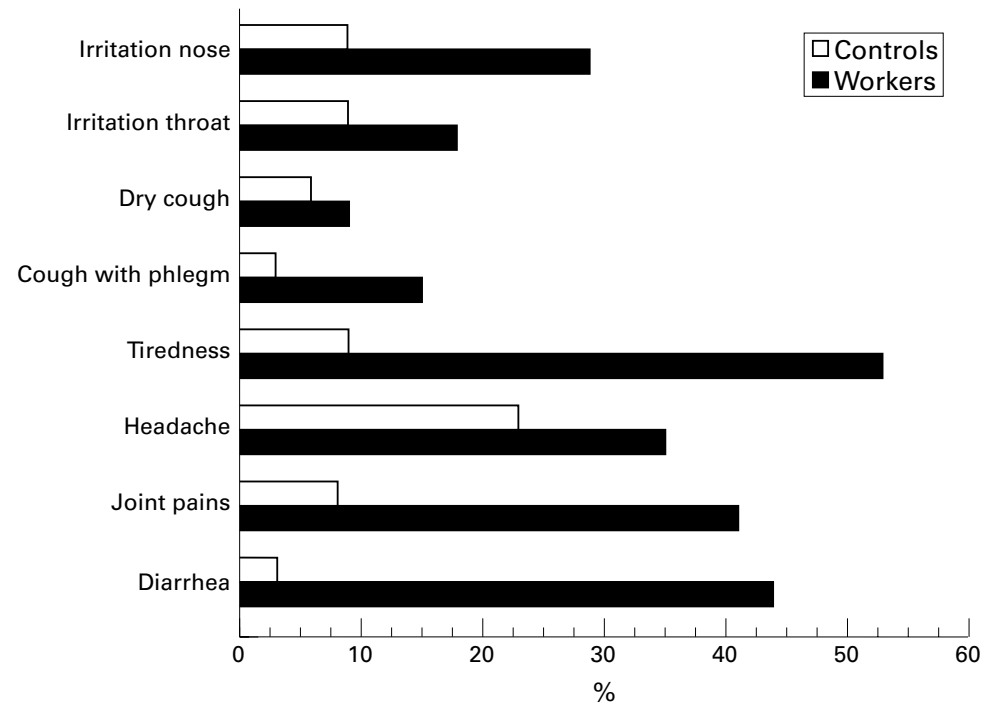

Extent of different symptoms reported by controls $(n=35)$ and sewage plant workers $(n=34)$.

processing of sludge. In general, the amounts of airborne endotoxin adjacent to water basins were relatively low $(n=7$, mean 17.6 , range $\left.3-39 \mathrm{ng} / \mathrm{m}^{3}\right)$. The highest values were found in the vicinity of sludge handling and during cleaning procedures $(n=6$, range 2-32 170 $\left.\mathrm{ng} / \mathrm{m}^{3}\right)$. The amounts of $(1 \rightarrow 3)-\beta-\mathrm{D}$-glucan at all work sites were low (maximum $3.6 \mathrm{ng} / \mathrm{m}^{3}$ ), all falling within the range of normal background concentrations. None of the workers carried respiratory protection devices during the work.

The figure reports the extent of different symptoms among sewage workers and controls. It was found that sewage workers had an increased incidence of airway symptoms, general symptoms, and diarrhoea. The differences were significant for irritation in the nose, joint pains, tiredness, and diarrhoea. When nonsmokers were analysed separately, the differences in airway symptoms between workers and controls were still present although less noticeable.

Table 2 reports spirometric values and airway responsiveness among workers and controls.

Table 2 shows that baseline $\mathrm{FEV}_{1}$ was the same in both groups. The methacholine induced decrease in $\mathrm{FEV}_{1}$ was significantly higher among sewage workers. When nonsmokers only were analysed $(n=18$ and 16 ; table 1), the mean (SD) difference was larger $(-6.1(5.4) v-3.5(2.9))$.

\section{Comments}

The results show that airborne endotoxin was present in the sewage treatment plants but

Table 2 Spirometry and airway responsiveness among controls and workers

\begin{tabular}{lcc}
\hline & $\begin{array}{l}\text { Controls } \\
\text { Mean (SD) }\end{array}$ & $\begin{array}{l}\text { Workers } \\
\text { Mean (SD) }\end{array}$ \\
\hline $\mathrm{n}$ & 35 & 34 \\
$\mathrm{FEV}_{1} \%$ of expected & $100.2(11.9)$ & $101.2(13.3)$ \\
$\mathrm{FVC}_{\mathrm{FEV}} / \mathrm{FVC}$ & $106.1(12.0)$ & $105.2(12.0)$ \\
$\Delta \mathrm{FEV}_{1}$ after methacholine & $78.3(5.5)$ & $79.7(5.3)$ \\
\hline
\end{tabular}

$(1 \rightarrow 3)-\beta-\mathrm{D}$-glucan did not exceed normal background values. This is reasonable, as the dominant flora in waste water are gram negative bacteria and the conditions in sewage water do not favour mould growth. Environments with organic dust and high concentrations of $(1 \rightarrow 3)-\beta-D$-glucan are wood processing industries and cotton mills, where values $<160 \mathrm{ng} / \mathrm{m}^{3}$ have been measured.

The results from the study confirm data from previous investigations on an increased incidence of airway symptoms, diarrhoea, and fatigue among sewage workers. ${ }^{5613}$ Similar symptoms have recently been found among waste collectors. ${ }^{14}$ The reason for the increase in symptoms can be interpreted as a mucosal inflammation caused by inhaled endotoxin. Endotoxin has a wide variety of important biological properties, and the effects after inhalation are relatively well understood. ${ }^{15}{ }^{16} \mathrm{Basi}-$ cally, it produces an inflammatory response with neutrophilia and acts as an adjuvant for antigens in immune defence.

Endotoxin is now generally accepted to be one of the most important bioactive components of organic dusts; dose-response relations have been found for a number of acute and some chronic effects, and guidelines for endotoxin exposure in the environment have been suggested. ${ }^{17}$ For effects on the gastrointestinal tract, inhalation of pure endotoxin has been shown to produce symptoms of abdominal pain and in some cases diarrhoea. ${ }^{18}$ The same effect is reported after ingestion of gram negative bacteria. ${ }^{19}$ As the particle size in the sewage water aerosol is larger than that in dry organic dusts, there is a considerable deposition in the nasopharyngeal area, resulting in deposition in the gastrointestinal tract with subsequent inflammatory response in the gut mucosa as well.

As no personal data could be obtained, dose-response relations could not be evaluated.

By contrast with the findings in this study, one previous study reported a decrease in pulmonary function among workers in a sewage treatment plant. $^{7}$ No exposure measurements were made in that study but, hypothetically, endotoxin concentrations could have been higher than in the plants studied here. A decrease in lung function during a workshift among cotton workers ${ }^{20} 21$ as well as among normal subjects sensitive to cotton dust ${ }^{22}$ has been related to endotoxin concentrations. This is also true for lung function decrease over the workshift and the decrease over time among grain workers. $^{23}$

Some previous studies have suggested that the effects found among sewage workers are caused by exposure to chemicals. This may be the case under certain circumstances but, in the plants examined here, no effluent from the chemical industry was present. Furthermore, the symptoms found are similar to those previously reported among household compost workers, for whom no chemical exposure takes place. $^{24}$

A dominant feature of exposure to organic dusts and endotoxin is the excessive fatigue reported by the exposed people. A likely mech- 
anism for this symptom is the release of inflammatory mediators at the site of inflammation, with subsequent transportation through the blood to the brain. ${ }^{25}{ }^{26}$ This is also the mechanism behind the development of toxic pneumonitis after inhalation of organic dusts contaminated with endotoxin or pure endotoxin. ${ }^{18}$

In summary, the results from the study show an increased prevalence of symptoms of airways inflammation among workers in sewage treatment plants. General symptoms in the form of fatigue and diarrhoea were also more common in comparison with controls. In view of previous experience on the effects of inhaled endotoxin and endotoxin contaminated organic dusts, it is likely that the effects are caused by bacterial endotoxins. Values at several of the work sites exceeded suggested guidelines.

The work was funded by grants from the Swedish Work Environment Fund (contract 94-0505), the Swedish Water and Sewage Association, and the participating municipalities.

1 Anders W. Die Berliner Kanal Betriebsarbeiter. Zeitschrift für Hygiene 1954;139:341-71.

2 Clark CS, Bjornson HS, Schwartz-Fulton J, et al. Biologica health risks of associated with the composting of wastewater treatment plant sludge. Fournal of Water Pollution Control Federation 1984;56:1269-76.

3 Clark CS, Linnemann CCJr. The use of serum antibody as a means to determine infections from exposure to wastewaters and refuse. Critical Review of Environmental Control 1986;16:305-26.

4 Brugha R, Heptonstall J, Farrington P, et al. Risk of hepatitis A infection in sewage workers. Occup Envion Med 1998; tis A infection.

5 Lundholm M, Rylander R. Work related symptoms among sewage workers. Br f Ind Med 1983;40:325-9.

6 Scarlett-Kranz JM, Babish JG, Strickland D, et al. Health among municipal sewage and water treatment workers.

7 Zuskin E, Mustafbegovic J, Schacter EN. Respiratory function in sewage workers. Am F Ind Med 1993;23:751-61.
8 Williams DL Overview of $(1 \rightarrow 3)$ - $\beta$-D-glucan immunobiology. Mediators of Inflammation 1997;6:247-50.

9 Tamura H, Arimoto Y, Tanaka S, et al. Automated kinetic assay for endotoxin and $(1 \rightarrow 3)-\beta-D$-glucan in human blood. Clin Chim Acta 1994;226:109-12.

10 Rylander R, Peterson Y, Donham KJ. Questionnaire evaluating organic dust exposure. Am f Ind Med 1990;17: 121-6.

11 Knudson, RJ. Lebowitz MD, Holberg CJ, et al. Changes in normal maximal expiratory flow-volume curve with growth and aging. Am Rev Respir Dis 1983;127:725-34.

12 Yan K, Salome C, Woolcock AJ. Rapid method for measurements of bronchial responsiveness. Thorax 1983;38:760-5.

13 Nethercott JR, Holness DL. Health status of a group of sewage treament workers in Toronto, Canada. Am Ind Hyg Assoc F 1988;49:346-50

14 Ivens UI, Ebbehøj N, Poulsen OM, et al. Season, equipment, and job function related to gastrointestinal problems in waste collectors. Occup Environ Med 1997;54: 861-7.

15 Sandström T, Bjermer L, Rylander R. Lipopolysaccharide inhalation in healthy subjects increases neutrophils, lymphocytes, and fibronectin levels in bronchoalveolar lavage fluid. Eur Respir f 1992;5:992-6.

16 R Burrell. Human responses to bacterial endotoxin. Circulatory Shock 1994;43:137-53.

17 Rylander R, Jacobs RR. Endotoxins in the environment: a criteria document. Int f Occup Environ Health 1997;3:S148

18 Thorn J, Rylander R. Inflammatory response after inhalation of bacterial endotoxin assessed by the induced sputum technique. Thorax 1998;53:1047-52.

19 Waslien CI, Calloway DH, Margen S. Human intolerance to bacteria as food. Nature 1969;221:84-5.

20 Haglind P, Rylander R. Exposure to cotton dust in an experimental cardroom. Br f Ind Med 1984;41:340-5.

21 Rylander R, Haglind P, Lundholm M. Endotoxin in cotton dust and respiratory function decrement among cotton workers in an experimental cardroom. Am Rev Respir Dis 1985;131:209-13.

22 Castellan RM, Olenchock SA, Kinsley KB, et al. Inhaled endotoxin and decreases in spirometric values: an exposure-response relation to cotton dust. $N$ Engl F Med 19987;317:605-10.

23 Schwartz DA, Thorne PS, Yagla SJ, et al. The role of endotoxin in grain dust induced lung disease. Am f Respir Crit Care Med 1995;152:603-8.

24 Lundholm M, Rylander R. Occupational symptoms among compost workers. $\mathcal{F}$ Occup Med 22:256-7.

25 Dunn AJ. Endotoxin-induced activation of cerebral catechoDunn AJ. Endotoxin-induced activation of cerebral catecho-
lamine and serotonin metabolism: comparison with lamine and serotonin metabolism: comparison

26 Michel J, Duchateau G, Plat B, et al. Blood inflammatory response to inhaled endotoxin in normal subjects. Clin Exp Allergy 1995;25:73-9. 